\title{
Onset of the Summer Monsoon over the Southern Vietnam and its Predictability
}

\author{
Xuan Thanh Pham*§ \\ *Institute of Geophysics, Vietnam Academy of Science and Technology, Hanoi, Vietnam
}

\section{Bernard Fontaine $^{\circ}$ and Nathalie Philippon $^{\circ}$}

${ }^{\circ}$ Centre de Recherches de Climatologie, UMR 5210, CNRS, University of Burgundy, Dijon, France

$\S$ author to whom correspondence must be addressed: pxthanh@igp.ncst.ac.vn 


\begin{abstract}
The summer monsoon onset over southern Vietnam is determined through a new criterion based on both in situ daily rainfall at 6 selected stations provided by the Institute of Meteorology and Hydrology, Vietnam, and the zonal component of the wind at $1000 \mathrm{hPa}$ from the National Center for Environmental Prediction/Department of Energy reanalysis 2 (NCEP/DOE-II). Over the period 1979-2004, the summer monsoon onset mean date is on 12 May, with a standard deviation of 11.6 days. The temporal and spatial structures of the atmospheric conditions prevailing during the onset period are detailed. Clear changes are seen in the zonal wind (strengthened over the Bay of Bengal and changed from negative to positive over South Vietnam) and in convection (deeper), in association with an intensification of the meridional gradients of sea level pressure at $1000 \mathrm{hPa}$ and of moist static energy at $2 \mathrm{~m}$ over Southeast Asia. The predictability of onset dates is then assessed. Cross validated hindcasts based upon 4 predictors linked to robust signals in the atmospheric dynamics are then provided. They are highly significant when compared to observations (56\% of common variance). Basically, late (early) onsets are preceded in March-April by higher (lower) sea level pressure over the East China Sea, stronger (weaker) southeasterly winds over southern Vietnam, decreasing (increasing) deep convection over the Bay of Bengal and the reverse situation over Indonesia $\left(120^{\circ} \mathrm{E}-140^{\circ} \mathrm{E}, 0-10^{\circ} \mathrm{S}\right)$.
\end{abstract}




\section{Introduction}

Vietnam, and more largely the Indochina Peninsula, is a unique region where the monsoon activity reflects a transitional feature of two distinct monsoon subsystems of the Asian monsoon: the south Asian monsoon and the east Asian monsoon (Pham and Phan, 1993; Zhang et al, 2002). In general, in Vietnam there are two main seasons separated by a transition period: the rainy season from May to September-October and the dry season from October-November to April. From mid-April to mid-May, four branches of the prevailing winds with different sources and properties affect directly the weather regime over Vietnam: in low levels it must be distinguished (1) the northeasterly branch from eastern regions of the China sea, which originates in the polar air; (2) the south easterlies associated with the subtropical ridge over the western Pacific; (3) the westerlies over the equatorial eastern Indian Ocean, which stretch northeastward in early May as south westerlies; in the upper troposphere (4) the subtropical westerly flow stretching from the northern Indian subcontinent to the Indochina Peninsula.

Despite the monsoon influence, and because of the heterogeneous topography and latitudinal extent, the climate across Vietnam is very contrasted. In Northern Vietnam, the opposition between the rainy and dry seasons is not so marked in terms of rainfall. For example, by the end of the dry season (March-April), there are cloudy days with light rains of 20-30mm under the influence of cold fronts. During the transition period from the dry season to the wet season there is no clear reversal of the prevailing winds. In summer, because of the effect of the low pressure centre over the Bay of Bacbo (Vietnam), the south westerly flow changes to southerly or south easterlies (Pham and Phan, 1993). For coastal areas and parts of the central highlands facing north-east, the season of maximum rainfall is delayed to September-December. Inversely, the climatic regime of the Southern Vietnam is better representative of the monsoonal climates with two distinct seasons: the rainy season from 
May to October with prevailing southwesterlies, and the dry season from November to April with northeasterlies. This is the reason why this paper focuses on the southern Vietnam.

The term Asian summer monsoon (ASM) usually refers to the planetary-scale monsoon system over Asia (Xu and Chan, 2001). Tao and Chen (1987) contend that the Asian monsoon sets up first over the South China Sea (SCS), usually in the middle May, then moves northward to the China mainland and the western Pacific Ocean to the south of Japan, and finally moves southwestward to the Bay of Bengal and Indian Peninsula. However, Wu and Zhang (1998) and Mao et al. (2004) found that onset first establishes over the eastern Bay of Bengal during the first pentad of May, over the South China Sea in the fourth pentad of May and over the South Asian in the first two pentads of June. The date of summer monsoon onset over the Indochina Peninsula was found in the first two pentads of May (Matsumoto, 1997; Wang and Ho, 2002; Zhang et al., 2002) or in late April - mid-May (Qian and Lee, 2000). A few recent studies have been devoted to this phenomenon which reveals close relationships with time evolution of the wind, temperature, and convection fields. The onset of the Asian summer monsoon is characterized by the establishment of deep moist convection and the change in direction of the prevailing winds (Lau and Yang, 1997; Wu and Zhang, 1998; Zhang et al., 2002), the westward and northward migration of the equatorial convective cloudiness maximum (Joseph et al., 1994), and the reversal of the meridional mean upper tropospheric $(200-500 \mathrm{hPa})$ temperature gradient ( $\mathrm{Li}$ and Yanai, 1996; Mao et al., 2004).

The main objective of this study is twofold : (1) determine the date of the Asian summer monsoon onset over the Southern Vietnam and (2) discuss its predictability. To achieve the first goal, long-term observed daily rainfall series from 6 stations in southern Vietnam will be employed to construct an original daily rainfall index. For reaching the second one, the daily NCEP/DOE II reanalysis data will be used to focus on atmospheric 
conditions associated with the onset, then precursory signals for the early/late onset years will be defined for investigating its predictability.

In section 2, data are described. Section 3 defines the summer monsoon onset and its dates of occurrence. We provide some statistics on the dates of onset and on the relevant aspects of rainfall and atmospheric field evolutions around these dates in Section 4. Section 5 focuses on onset dates predictability and prediction by presenting and discussing experimental hindcasts. Section 6 summarizes the results.

\section{Data}

In this study, the daily rainfall data originate from the Institute of Meteorology and Hydrology of Vietnam. For our purposes, we selected 6 stations over southern Vietnam : Bao Loc, Tay Ninh, Tan Son Nhat, Can Tho, Rach Gia and Ca Mau, from North to South. The three first stations describe the eastern part of the region while the three last ones refer to the western part. Table 1 and figure 1 display their geographic characteristics and locations. Over the selected study period $1979-2004$, these stations have less than $1 \%$ of missing data. These missing data were replaced by the mean climatological value. We derived a regional daily rainfall index by simply averaging the 6 stations. Figure 2 displays the climatology of this daily rainfall index.

To describe the atmospheric conditions at regional scale associated with the rainy season onset, we have chosen the NCEP/DOE AMIP-II Reanalysis (R-2) data. In this version, the modeled precipitation have been replaced by observed (satellite + raingauges) 5day precipitation (Kanamitsu et al., 2002). R-2 improves upon the NCEP/NCAR Reanalysis (R-1) by fixing the errors and updating the parameterizations of the physical processes. Maurer et al. (2001) found that R-2 provides more accurate pictures of soil wetness, near 
surface temperature and surface hydrology budget over land, and radiation fluxes over Ocean. The selected variables include both atmospheric and surface information from 1979 to 2004: atmospheric variables are the wind ( $\mathrm{U}$ and $\mathrm{V}$ components) field at $1000 \mathrm{hPa}$, and the mean sea level pressure (MSLP), all available in a horizontal resolution of $2.5^{\circ}$ latitude $\mathrm{x}$ $2.5^{\circ}$ longitude; surface parameters are the temperature $(\mathrm{T})$, and specific humidity (q) fields at $2 \mathrm{~m}$, available in a horizontal resolution of $1.9^{\circ}$ latitude $\times 1.9^{\circ}$ longitude. These three parameters were combined to compute the Moist Static Energy field. It is obtained following:

$$
\mathrm{MSE}=\mathrm{Cp} \cdot \mathrm{T}+\mathrm{L} \cdot \mathrm{q}+\mathrm{g} \cdot \mathrm{Z}
$$

where $\mathrm{CpT}$ is the enthalpy, $\mathrm{Cp}$ the specific heat of dry air at constant pressure $(\mathrm{Cp}=1,004 \mathrm{~J}$ $\mathrm{K}^{-1} \mathrm{Kg}^{-1}$ ) and $\mathrm{T}$ the temperature (Kelvin) at $2 \mathrm{~m}$. Lq is the latent energy associated with evaporation and condensation of water, with $\mathrm{L}$ the latent heat of evaporation $(\mathrm{L}=2,501 \mathrm{~J} / \mathrm{g})$ and $\mathrm{q}$ the specific humidity at $2 \mathrm{~m}$, and $\mathrm{gZ}$ is the gravitational-potential energy, with $\mathrm{g}$ the gravitational acceleration and $\mathrm{Z}=2$. The MSE content close to the earth surface is considered to investigate the possible influence of energy amounts in the low atmospheric levels on the monsoon onset.

Deep convection has been documented using the daily NOAA Interpolated Outgoing Longwave Radiation (OLR) data in a $2.5^{\circ} * 2.5^{\circ}$ resolution and in a version where the gaps have been filled with sophisticated temporal and spatial interpolation (Liebmann and Smith, 1996). Notice however that OLR daily values are not direct measurements of organized convective systems because it often exists many individual cloud-types embedded within a common cirrostratus canopy. Inversely, in clear-sky situations, OLR measures the direct emission from land or oceanic surfaces.

\section{Determination of onset dates}


According to the point of view of the climatologists, the wet season over southern Vietnam takes place from May to October, while the dry season occurs from November to April. Figure 2 presents the 5-day running climatology of the regional rainfall index for the 26-year study period as a black thick line. Jointly, the climatology of the daily zonal wind above the South Vietnam (grid point located at $10-12.5^{\circ} \mathrm{N}, 105-107.5^{\circ} \mathrm{E}$ ) is provided as a thin gray line. This diagram shows that the transition from the dry to the wet season from April to May is characterized by (1) a sudden increase of the daily rainfall from 3 mm.day ${ }^{-1}$ in April to about 7 mm.day $^{-1}$ in May, and (2) changes in the zonal wind component from negative (easterlies) to positive (westerlies) values.

The date of monsoon onset has been defined in various ways. Holland (1986) defined the onset of the Australian summer monsoon through changes of the prevailing winds. Some other authors have defined the onset by focusing on precipitation only, fixing some threshold values of precipitation rate (Tao and Chen, 1987; Matsumoto, 1997; Wang and Ho, 2002; Zhang et al., 2002). The combination of wind and precipitation or convection activity data has also been used (Lau and Yang, 1997; Qian and Lee, 2000; Ding and Yanju, 2001). Recently, the reversal of the meridional temperature gradient in the upper troposphere (200$500 \mathrm{hPa}$ ) has been shown as an interesting signal of the monsoon onset (Li and Yanai, 1996; Mao et al., 2004).

In this paper, the onset date is defined for the 26 available years of the reference period given that the following conditions are verified:

1) The daily amount of our rainfall index exceeds 5 mm.day ${ }^{-1}$ and these conditions persist for at least 5 days.

2) The daily mean of our zonal wind index exceeds $0.5 \mathrm{~m} / \mathrm{s}$.

These 2 conditions allow determination of the first occurrence of monsoon rains within the monsoon flow regime and are sufficient for depicting correctly the onset. The addition of 
a persistence criterion such as "Within the consecutive 20 days, the number of the days with rainfall greater than $5 \mathrm{~mm}$ day exceeds 10 days" used by Zhang et al. (2002) does not change the onset dates except in 1989.

The onset dates as defined above are displayed for each year of the study period in Table 2. The earliest onset occurred in 1979 (April, the 19th) and the latest one in 1993 (June, the 9th). The mean date is the 12 of May with a standard deviation of 11.6 days. This is consistent with previous results obtained for the Indochina region : 1-15 May (Qian and Lee, 2000), 6-10 May (Wang and Ho, 2002), and 9 May (Zhang et al., 2002).

The mean annual evolutions of the daily rainfall index are displayed in figure 3 for the 8 earliest (solid) and 8 latest (dashed) onset dates observed over the period 1979-2004 along with the significant differences (asters) at 95\% according to a Student T-test. It well appears that early (late) onsets are associated with significant above (below) than normal precipitation in spring and summer, i.e., before and during the monsoon season. This implies that the date of onset can be viewed as a simple leading signal of the quality of the following rainy season: an early (late) date tends to precede rainfall excess (deficit).

\section{Atmospheric conditions associated with the monsoon onset.}

In order to reveal changes in the atmospheric conditions around the monsoon onset, we stratified the daily fields of MSE, MSLP, OLR and wind as a function of the successive onset dates on the reference period. The onset day is referred to as day 0 . Then, the mean fields before and after the onset day are obtained by averaging values from day " -15 " to day “-1" and from day "0" to day " $+14 "$, respectively. Figures 4 and 5 display the mean MSE, 
MSLP, OLR and wind conditions before and after the monsoon onset as defined previously. In figures 4 and 5bd, MSE, MSLP, and OLR values lower than $355 \mathrm{KJ} / \mathrm{Kg}, 1011 \mathrm{hPa}$, and $240 \mathrm{Wm}^{-2}$ are marked by dashed lines. Figure 6 presents differences between the 15-day periods following and preceding each onset (i.e. differences between Figure 5 and Figure 4). Such 'after-before' signals point out the anomaly pattern evolutions significantly linked to the onset. In Figure 6, the positive (negative) tendencies are displayed with solid (dashed) lines, and shadings denote differences significant at $\mathrm{p}=0.05$ according to a Student T-test.

Before the monsoon onset, two MSE maxima $(375 \mathrm{KJ} / \mathrm{Kg}$ ) appear over the west and north parts of the Bay of Bengal (Figure 4a). After the onset, they extend over the whole bay while an another maximum has developed over the South China Sea (SCS, Figure 4c). However, Figure 6a reveals that at the time of the onset, changes in the MSE field are at first of hemispheric scale, with MSE increase over $30^{\circ} \mathrm{N}-35^{\circ} \mathrm{N}$ and decrease over $15^{\circ} \mathrm{S}-20^{\circ} \mathrm{S}$, the largest differences being recorded over eastern China and Australia.

These MSE tendencies are associated with positive (negative) tendencies in MSLP over the same belts : $30^{\circ} \mathrm{N}-35^{\circ} \mathrm{N}\left(15^{\circ} \mathrm{S}-20^{\circ} \mathrm{S}\right)$ with maximums (minimums) over eastern China (the middle of Indian Ocean) (Figure 6b). These maps show that at the moment of onset, robust signals of regional extent can be captured in the MSE and MSLP meridional gradients. Such gradients are well known to drive monsoon energetics and dynamics either directly via changes in low-level MSE values and pressure gradient force (hence horizontal wind field) or indirectly via their new vertical arrangement.

These changes in the low-levels energy content are to be associated with those observed in the $1000 \mathrm{hPa}$ wind field (Figure 5ac). The transition from before to after the onset is first characterized by an outburst of southwesterlies over the Bay of Bengal (Figure 6c). Before the onset (Figure 5a), one can notice the weakness of these winds whereas after the onset (Figure 5c), they stretch deep into Indochina. This is concomitant to the deepening or 
settlement of low pressure centers $(1002 \mathrm{hPa})$ over the north of India and of the Bay of Bengal. Secondly, the time of onset is also characterized by the settlement of southerlies in place of easterlies over the South China Sea. The easterlies were associated with the subtropical ridge in the western Pacific (Figure 5a) while the southerlies are to be linked with the appearance of a low pressure center over the South China Sea and the retreat of the subtropical ridge (Figure5c). Therefore, during the monsoon onset, the direction of the prevailing winds over southern Vietnam is changed from southeasterlies to southwesterlies, the later conveying water vapor from the Indian Ocean and the Malay archipelago and resulting in a rapid MSE increase.

Lastly, the OLR mean fields (Figure 5bd) allow us to better detail the evolution of the tropical convection associated with the monsoon onset. Before the monsoon onset, two OLR minima (i.e., 2 areas of deep convection) appear over Sumatra and the Indonesia whereas northern regions of the Bay of Bengal and SCS register OLR maxima. After the onset, the minimum OLR over Sumatra extends northward while the minimum OLR over Indonesia declines. The highest convective areas $\left(<210 \mathrm{Wm}^{-2}\right)$ cover the southeastern coast of Bay of Bengal and the southwestern area of Vietnam and Cambodia. Figure 6d emphasizes these positive and negative OLR tendencies over Indonesia and the Bay of Bengal and the SCS respectively, suggesting a northward migration of the equatorial convective cloudiness maximums. These observations are in good agreement with Zhang et al. (2002), who found that the northward extension and intensification of strong convection centers over Sumatra might be responsible for the outburst of the strong monsoon rainfall over the Indochina Peninsula.

All these results (figures 4-6) show that robust atmospheric features of sub-regional scale are in phase with the dates of onset (i.e., pressure and MSE gradients, OLR and wind fields). A statistical prediction of onset dates based on such signals is hence feasible. The following 
section illustrates this issue.

\section{Hindcast of the summer monsoon onset over the southern Vietnam}

The experimental hindcasts of onset dates were performed using multivariate linear regression (MLR) analyses. The predictand, i.e., the value to be predicted, is the regional onset date index presented in Table 2. The predictors are 10 regional indexes of Moist Static Energy, Mean Sea Level Pressure, and of the wind velocity (i.e. $\sqrt{U^{2}+V^{2}}$ ) in low levels, and OLR considered from the 18th to the 21st pentad of the year (30 March - 19 April) i.e. before the earliest onset date detected over the study period. All these predictors have a physical sense. They describe monsoon energetics and dynamics along the meridional plane in terms of gradients of sea level pressure and moist static energy near the surface. They take also into account some features significantly linked to the onset such as wind changes and deep convection shift. More precisely, the 10 potential predictors are: (1) MSE over ChinaJapan; (2) MSE over Australia; (3) MSLP in the Indian Ocean; (4) MSLP over the Eastern China Sea; (5) wind over the Arabian sea; (6) wind over the Bay of Bengal; (7) wind over the southern Vietnam ; (8) OLR over the Bay of Bengal; (9) OLR over the South China Sea, and (10) OLR over Indonesia (see boxes on figure 6).

The selection of the 4 (among 10) best predictors is through a stepwise procedure after application of a leave-three-out cross-validation to the 10 potential predictors. Crossvalidation ensures robust skills since the predictive information of the year to predict and of the year after and before is not used. The regression coefficients for a given year are therefore calculated on the remainder 23 years (26-3). This minimises potential skill inflation which may arise from the multi-annual persistence of predictor and/or predictand conditions. This allows us to provide better estimates of the true forecast skill (Michaelsen, 1987; Barnston, 1994). 
In Parallel, a linear discriminant analysis (LDA) has also been applied to predict the membership of the onset dates in three categories (early, normal, late) from the same four predictors as the ones selected for the MLR model. This method is designed to distinguish between discrete groups or categories by obtaining a linear combination of predictors which provides the best possible separation of groups. The approach is to maximise the ratio of the between-category to within-category sums of squares using a linear statistical analysis of the potential predictors (Keenan, 1986).

The 4 best predictors are the MSLP index averaged over Eastern China Sea $\left(20^{\circ} \mathrm{E}-\right.$ $140^{\circ} \mathrm{E}, 30^{\circ} \mathrm{N}-35^{\circ} \mathrm{N}$, Figure $6 \mathrm{~b}$ ) during the $18^{\text {th }}$ pentad (SLP\#18); wind over the southern Vietnam $\left(105^{\circ} \mathrm{E}-115^{\circ} \mathrm{E}, 10^{\circ} \mathrm{N}-15^{\circ} \mathrm{N}\right.$, Figure $\left.6 \mathrm{c}\right)$ in the $20^{\text {th }}$ pentad (wind\#20); OLR over the Bay of Bengal $\left(90^{\circ} \mathrm{E}-100^{\circ} \mathrm{E}, 10^{\circ} \mathrm{N}-20^{\circ} \mathrm{N}\right)$ during the $18^{\text {th }}$ pentad (OLR\#18), and over Indonesia $\left(100^{\circ} \mathrm{E}-120^{\circ} \mathrm{E}, 0-10^{\circ} \mathrm{S}\right)$ in the $20^{\text {th }}$ pentad $(\mathrm{OLR} \# 20)$ (figure $6 \mathrm{~d}$ ). Regression coefficients and associated statistics are displayed in Table 3. The coefficients indicate that late onset (the reverse is observed for abnormally early dates) tend to be preceded by:

1. growing MSLP over the China Sea (positive coefficient). This denotes decreasing meridional gradients which prevent the entrance of southwesterly flows possibly due to an influence of polar air;

2. increasing southeasterlies over southern Vietnam (positive), associated with a westward penetration of the subtropical ridge from the western Pacific;

3. a reinforcement of deep convection over the Indonesia in mid-April (negative) and a vanishing over the Bay of Bengal in early April (positive).

Figure 7 presents the scatter plot between observed and (cross-validated) hindcasted onset dates for each year. It is noteworthy that the correlation coefficient is high and significant at the $1 \%$ level $(\mathrm{R}=0.75)$ although the onset dates of years $1991,1993(1979,1982)$ are 
clearly estimated too early (too late) by the statistical model. Lastly, table 4 confirms the accuracy of the skill obtained when yearly onsets are classified into 3 categories: 16 onsets out of 26 are well classified and one observes only a strong error (a early observed onset hindcasted late). The linear error in probability space skill-score (LEPS, Ward and Folland, 1991; Potts et al., 1996) measures the error in probability space as opposed to measurement space. Note that the LEPS score can be applied to both continuous and categorical forecasts and is bounded between $-100 \%$ and $200 \%$, with scores greater (less) than zero indicating that the forecast is more (less) skillful than climatology. It produces robust, equivalent skill assessments that do not suffer from non-linearity complications, and is not sensitive to the number of categories a priori defined. It is hence less biased than the RMSE. In this study LEPS reaches $52 \%$.

\section{Conclusion}

The goal of this study was to define an objective index of monsoon onset over the southern Vietnam and assess the statistical predictability of its date of occurrence over the period 1979-2004. To that end we used different independent datasets, namely OLR from the NOAA and selected variables from the NCEP/DOE2 atmospheric reanalyses. Then we used a methodological framework based on a semi-objective selection of predictors. The main features of the results are the following:

1) The climatological monsoon onset over southern Vietnam occurs around 12 May although in individual years, the dates range from late-April to early-June, with a standard deviation of 11.6 days. The onset of the summer monsoon is characterized by robust changes in the zonal wind at $1000 \mathrm{hPa}$ (easterlies then westerlies) in association with a northward extension of tropical deep convection from Sumatra. After an early (late) onset, the following rainy season tends to register rainfall excess 
(deficit).

2) A close relationship exists between the date of the monsoon onset and the evolution of atmospheric conditions. Basically a too late onset year is preceded by: (1) increasing SLP over the South China Sea, and decreasing meridional gradients, which prevent a too rapid northeastward penetration of southwesterlies; (2) increasing southeasterlies over southern Vietnam, associated with a westward extension of the subtropical ridge over the western Pacific; (3) decreasing convection over the Bay of Bengal in early-April then increasing deep convection over the Indonesia at the mid of April.

3) These results allowed skillfull cross-validated hindcasts of onset dates based on these atmospheric signals: the correlation coefficient achieved using multivariate linear regression analyses is high $(\mathrm{R}=0.75)$; the linear error in probability space skill-score after linear discriminant analysis reaches $52 \%$.

This statistical study shows that prediction of onset dates based on robust atmospheric features of sub-regional scale is feasible. So the first objective will be to evaluate the predictability of onset dates by adding in the pool of potential predictors more specific descriptors of the intraseasonal variability in April-May using the multiscale information provided by the hydrological and meteorological services of Vietnam, in order to provide and test operational forecasts. Moreover, signals associated with the onset and lasting the whole rainy season open up a whole range of possibilities for the rainy season prediction in South Vietnam and elsewhere as in North Vietnam. The second goal will be to better explore the relationship between the date of monsoon onset and the quality of the following rainy season in this region. For example these preliminary results show that the dates of monsoon onset in South Vietnam are correlated $(\mathrm{r}=-0.39$, significant at $\mathrm{p}=0.10)$ with the respective 
seasonal rainfall amounts registered in the region. So part of onset information could be used in operational forecasts of seasonal rainfall amounts. The third challenge will be to use jointly atmospheric information from observations, reanalyzed datasets and numerical outputs since the direct seasonal rainfall forecasting from coupled climate models, as those involved in the DEMETER and ENSEMBLES experiments, is unskilful (Pham, 2008). Because the models reproduce better the atmospheric dynamics than precipitation the predictive scores can be significantly improved by using jointly the atmospheric dynamics outputs of these coupled models and the onset information in statistical models.

Acknowledgments. Dr Pham beneficed scholarship funding from the French Foreign Ministry and the CNRS in the framework of the international cooperative project "Sun Earth System interactions studies over Vietnam" headed by Dr Christine Mazaudier and Dr Le Huy Minh. Authors are grateful to the Institute of Geophysics, Vietnam Academy of Science and Technology, Hanoi, Vietnam and to the National Center for Environmental Prediction/Department of Energy for providing them with rainfall and atmospheric data respectively. 


\section{References}

Barnston A.G., and H.M. Van Den Dool, 1992: a degeneracy in cross-validated skill in regression-based forecasts. J Climate, 6, 963-977.

Ding Y., and L. Yanju, 2001: Onset and the evolution of the Summer Monsoon over the South China Sea during SCSMEX Field Experiment in 1998. J. Meteor. Soc. Japan, 79, 255-276.

Holland G.J., 1986: Interannual Variability of the Australian Summer Monsoon at Darwin: 1952-82. Mon. Wea. Rev., 114, 594-604.

Joseph P.V., Eischeid J.K., and R.J. Pyle, 1994: Interannual Variability of the Onset of the Indian Summer Monsoon and Its Association with Atmospheric Features, El niño, and Sea Surface Temperature Anomalies. J. Climate, 7, 81-105.

Kanamitsu M., Ebisuzaki W., Woollen J., Yang S.K., Hnilo J.J., Fiorino M., and G.L. Potter, 2002: NCEP-DOE AMIP-II Reanalysis (R-2). Bull. of the Atmos. Met. Soc., 83, 16311643.

Keenan T.D., 1986 : Forecasting Tropical Cyclone Motion Using a Discriminant Analysis Procedure. Mon. Wea. Rev., 114, 434-441.

Lau K.M., and S. Yang, 1997 : Climatology and Interannual Variability of the Southeast Asian Summer Monsoon. Adv. Atmos. Sci., 14, 231-245.

Li C., and M. Yanai, 1996: The Onset and Interannual Variability of the Asian Summer Monsoon in Relation to Land-Sea Thermal Contrast. J. Climate, 9, 358-375.

Liebmann B., and C.A. Smith, 1996: description of a complete (interpolated) outgoing longwave radiation dataset. Bull. Amer. Meteor. Soc., 77, 1275-1277.

Mao J., Chan J.C.L. and G. Wu, 2004: Relationship between the Onset of the South China Sea Summer Monsoon and Structure of the Asian Subtropical Anticyclone. J. Meteor. Soc. Japan, 82, 845-859. 
Matsumoto J., 1997 : Seasonal Transition of Summer Rainy Season over Indochina and Adjacent Monsoon Region. Adv. Atmos. Sci., 14, 231-245.

Maurer E.P., O'Donnell G.M., Lettenmaier D.P., and J.O. Roads, 2001: Evaluation of the land surface water budget in NCEP/NCAR and NCEP/DOE Reanalyses using an offline hydrologic model. J. Geophys. Res., 106 (D16), 17841-17862.

Michaelsen J., 1987: Cross-validation in statistical climate forecast models. J. Clim. and Appl. Met., 26, 589-600.

Pham N.T., and T.D. Phan, 1993 : Climate of Vietnam. Science and Technics Publishing house, Vietnam, 312p.

Pham X.T., 2008: Étude climatique de la mousson vietnamienne et applications à la prévision saisonnière, Université de Bourgogne, 207p.

Potts J.M., Folland C.K., Jolliffe I.T., and D. Sexton, 1996: revised LEPS scores for assessing climate model simulations and long-range forecasts. J. Climate, 9, 34-53.

Qian W., and D.K. Lee, 2000 : Seasonal march of Asian summer monsoon. Int. J. Climatol., 20, $1371-1386$.

Tao S.Y., and L.X. Chen, 1987: review of recent research on the East Asian summer monsoon in China. Monsoon Meteorology, C.P. Chang and T.N. Krishnamurti Eds, Oxford University Press, 60-92.

Wang B., and L. Ho, 2002: Rainy Season of the Asian-Pacific Summer Monsoon. J. Climate, 15, 386-398.

Ward N.M. and C.K. Folland, 1991: prediction of seasonal rainfall in North Nordeste of Brasil using eigenvectors of sea-surface temperature. Int. J. Clim., 11, 711-743.

Wu G., and Y. Zhang, 1998: Tibetan Plateau Forcing and the Timing of the Monsoon Onset over South Asia and the South China Sea. Mon. Wea. Rev., 126, 913-927.

Xu J., and J.C.L. Chan, 2001: First Transition of the Asian Summer Monsoon in 1998 and 
the Effect of the Tibet-Tropical Indian Ocean Thermal Contrast. J. Meteor. Soc. Japan, 79, 241-253.

Zhang Y., Lib T., Wang B., and G.Wu, 2002: Onset of the Summer Monsoon over the Indochina Peninsula: climatology and interannual variations. J. Climate, 15, 32063221. 


\section{Figures Caption}

Figure 1. Map locating the 6 rainfall stations used to construct the daily rainfall index over Southern Vietnam.

Figure 2. Climatology of daily indexes of rainfall (5-day running mean, in mm/day, black thick) and zonal wind (m/s, gray thin) over 1979-2004.

Figure 3. Mean 5-day rainfall amounts (in $\mathrm{mm}$ /day) during the 8 years registering the earliest / latest (solid / dashed) onsets over the period 1979-2004. The symbol '*' indicates that the Student T-test passes the 5\% significance level.

Figure 4. Mean fields of moist static energy in $\mathrm{KJ} / \mathrm{Kg}(\mathrm{a}, \mathrm{c})$ and sea level pressure in $\mathrm{hPa}$ (b,d) for 15-day period before (a,b) and after (c,d) the monsoon onset during 1979-2004 .

Figure 5. Mean surface wind in $\mathrm{m} / \mathrm{s}(\mathrm{a}, \mathrm{c})$ and outgoing longwave radiation in $\mathrm{Wm}^{-2}(\mathrm{~b}, \mathrm{~d})$ for 15-day period before (a,b) and after (c,d) the monsoon onset during 1979-2004 .

Figure 6. The after-minus-before composites of the moist static energy (a), mean sea level pressure (b), surface wind (c) and the outgoing longwave radiation (d). Shading indicates that the Student t-test passes the 5\% significant level. Boxes denote the location of regional indexes of atmospheric dynamics, energetics and OLR used as potential predictors of the rainy season onset date.

Figure 7. Scatter diagram between observed (x axis) and hindcasted (y axis) onset dates displayed in standardized values: positive/negative values for late/early onsets. Years are 
marked against the corresponding squares. 
Table 1. Selected stations in southern Vietnam (locations in Fig. 1)

\begin{tabular}{|l|c|c|c|c|}
\hline Stations & $\begin{array}{c}\text { Latitude } \\
\left({ }^{\mathbf{O}} \mathbf{)}\right.\end{array}$ & $\begin{array}{c}\text { Longitude( } \\
\left.{ }^{\circ} \mathbf{E}\right)\end{array}$ & $\begin{array}{c}\text { Altitude } \\
(\mathbf{m})\end{array}$ & Period \\
\hline Bao Loc & 11.47 & 107.80 & 850 & $1979-2004$ \\
\hline Ca Mau & 9.17 & 105.17 & 3 & $1979-2004$ \\
\hline Can Tho & 10.03 & 105.78 & 3 & $1979-2004$ \\
\hline Rach Gia & 10.00 & 105.08 & 2 & $1979-2004$ \\
\hline Tan Son Nhat & 10.82 & 106.67 & 9 & $1979-2004$ \\
\hline Tay Ninh & 11.32 & 106.07 & 10 & $1979-2004$ \\
\hline
\end{tabular}

Table 2. The onset dates of the summer monsoon over southern Vietnam

\begin{tabular}{|c|c|c|c|c|c|}
\hline \multirow{2}{*}{$\begin{array}{l}\text { Year } \\
1979\end{array}$} & \multicolumn{2}{|c|}{ Onset date } & \multirow{2}{*}{$\begin{array}{c}\text { Year } \\
1993\end{array}$} & \multicolumn{2}{|c|}{ Onset date } \\
\hline & 19 & Apr & & 9 & Jun \\
\hline 1980 & 19 & May & 1994 & 13 & May \\
\hline 1981 & 11 & May & 1995 & 13 & May \\
\hline 1982 & 1 & May & 1996 & 1 & May \\
\hline 1983 & 12 & May & 1997 & 4 & May \\
\hline 1984 & 5 & May & 1998 & 25 & May \\
\hline 1985 & 25 & May & 1999 & 23 & Apr \\
\hline 1986 & 11 & May & 2000 & 2 & May \\
\hline 1987 & 16 & May & 2001 & 13 & May \\
\hline 1988 & 21 & May & 2002 & 14 & May \\
\hline 1989 & 8 & May & 2003 & 4 & May \\
\hline 1990 & 16 & May & 2004 & 10 & May \\
\hline 1991 & 8 & Jun & mean & 12 & May \\
\hline 1992 & 7 & May & & & \\
\hline
\end{tabular}


Table 3. Results of experimental hindcasts: SLP\#18, wind\#20, OLR\#18, and OLR\#20 are the 4 selected predictors. Reg. C values are the regression coefficients for normalized series. Basic statistics are as follows: variance explained $\mathrm{R}^{2}=56 \%$, root mean square error RMSE $=$ 0.65 , absolute error ABSE $=0.53$, and BIAS $=-0.0011$.

\begin{tabular}{ccccc}
\hline Predictors & SLP\#18 & wind\#20 & OLR\#18 & OLR\#20 \\
\hline Reg. C & +0.30 & +0.39 & +0.50 & -0.43 \\
\hline
\end{tabular}

Table 4. Onset dates hindcasts versus observations after classification into 3 near equiprobable categories (early, normal and late), according to their dates of occurrence in standardized values (the 'normal' onset ranges from -0.34 to +0.35 ).

\begin{tabular}{|c|c|c|c|c|}
\hline & & \multicolumn{3}{|c|}{ Observations } \\
\hline & & early & normal & late \\
\cline { 2 - 5 } Hindcasts & early & 6 & 2 & 0 \\
\cline { 2 - 5 } & normal & 3 & 5 & 3 \\
\cline { 2 - 5 } & late & 1 & 1 & 5 \\
\hline
\end{tabular}


Figure 1

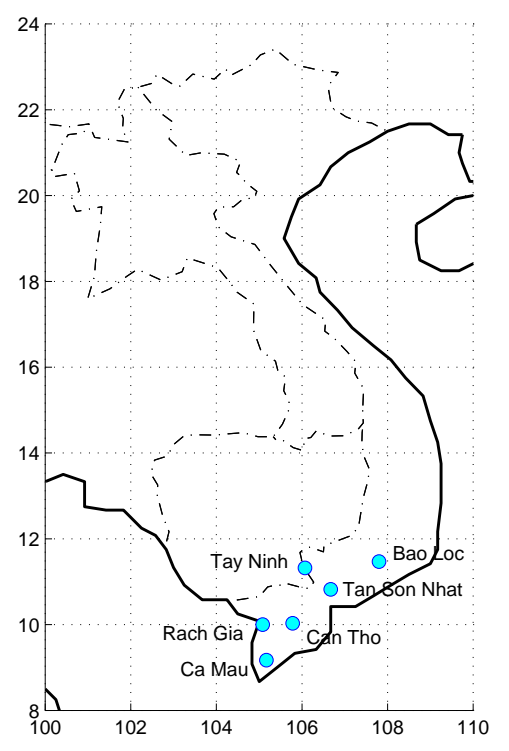


Figure 2

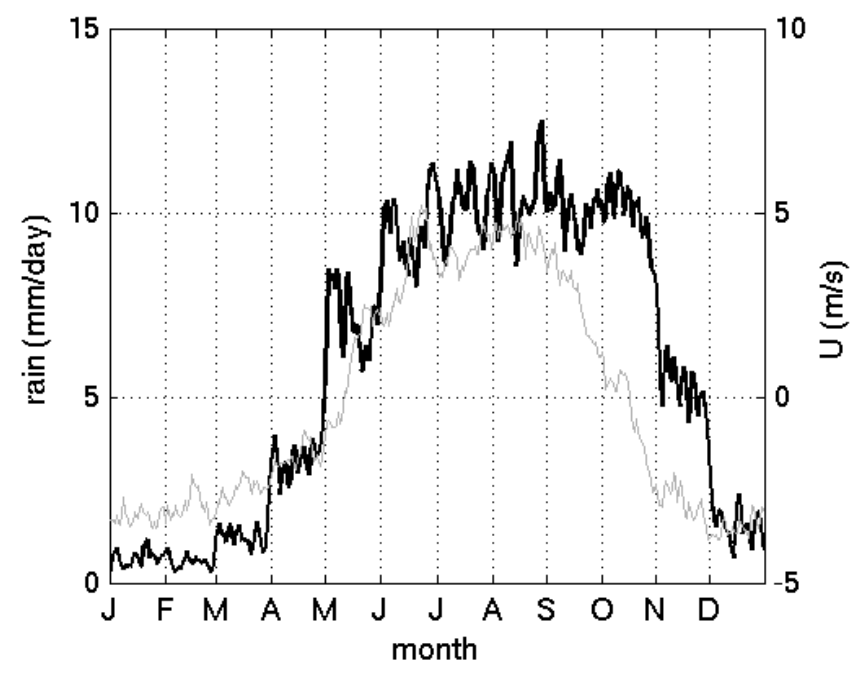


Figure 3

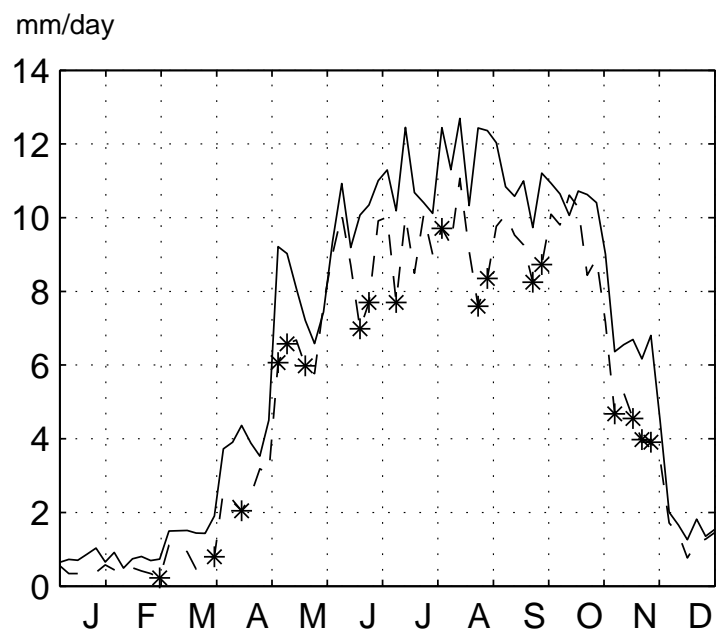


Figure 4

a)

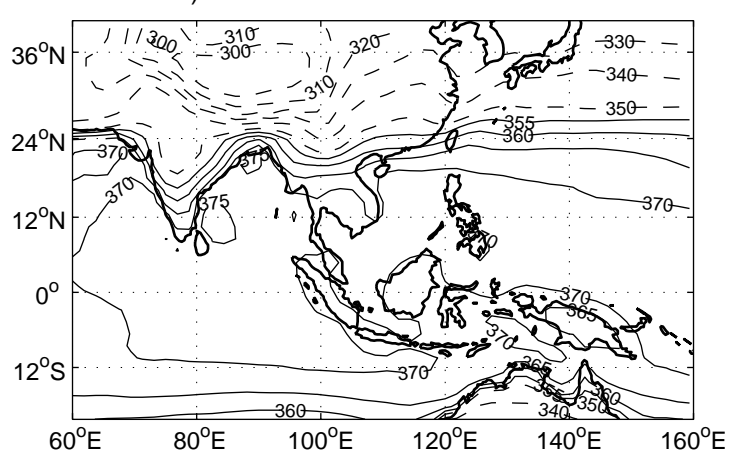

c)

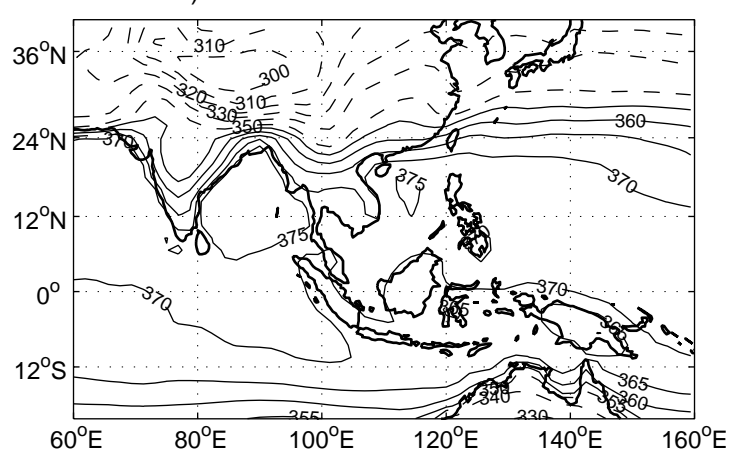

b)

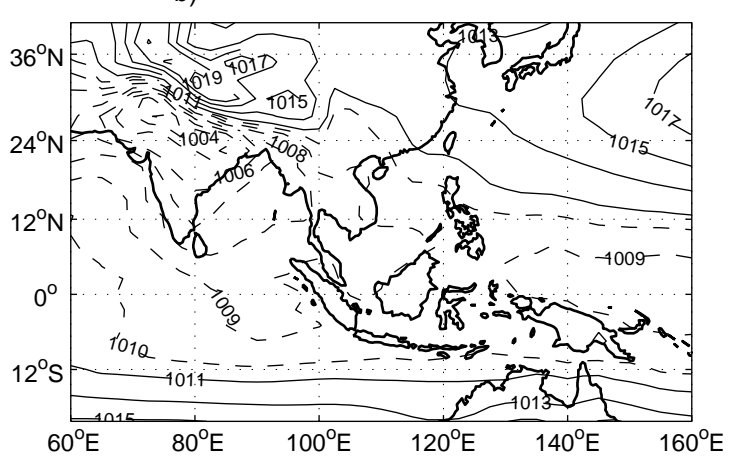

d)

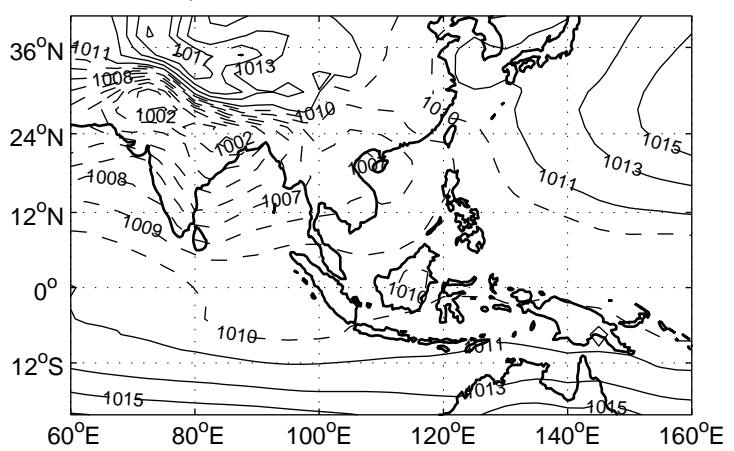


Figure 5

a)

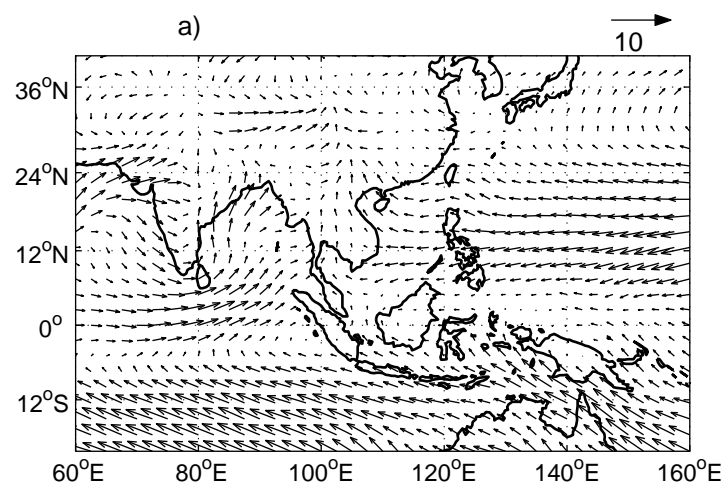

c)

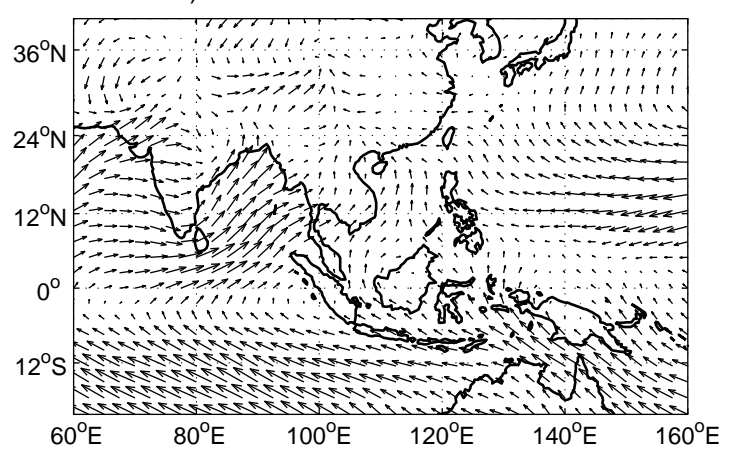

b)

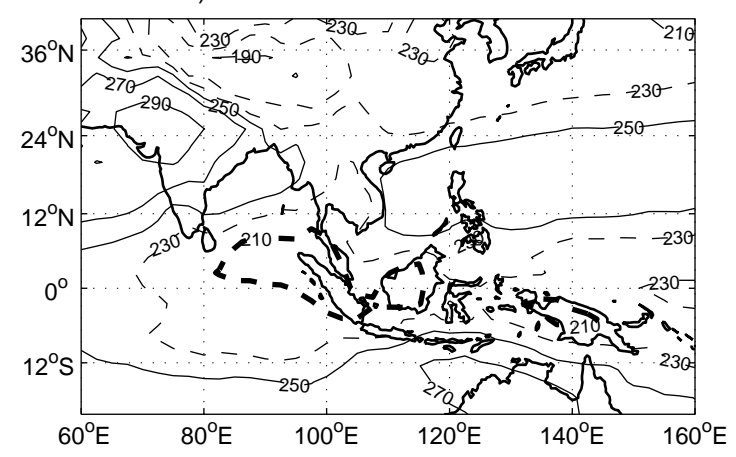

d)

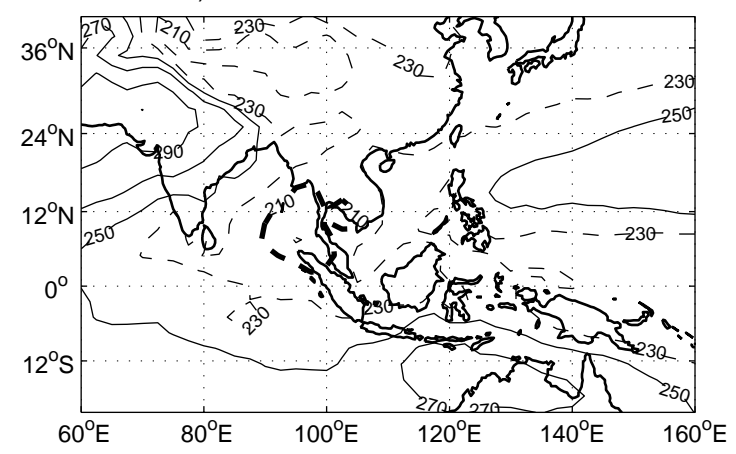


Figure 6

a)

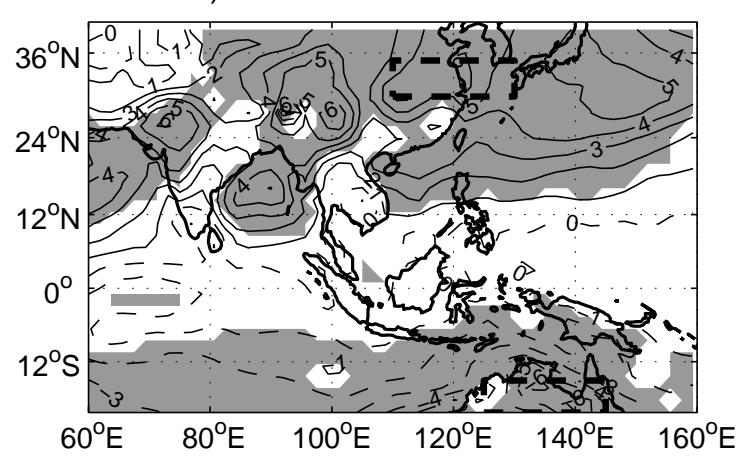

c)

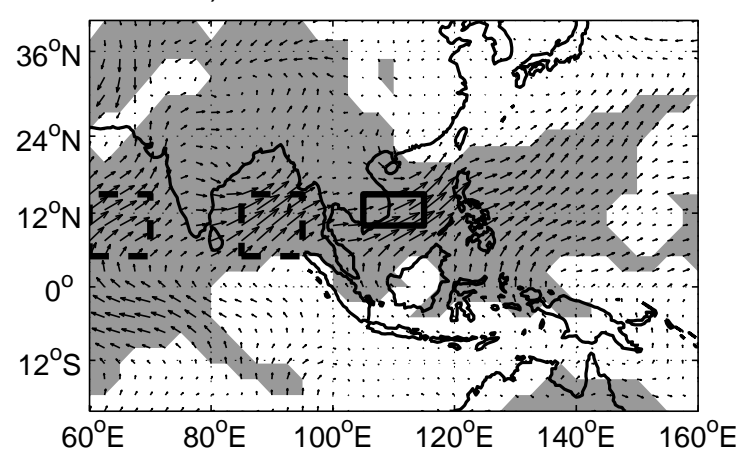

b)

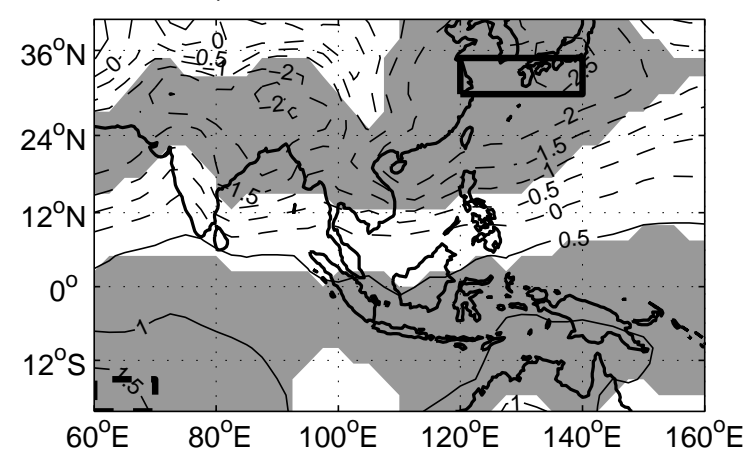

d)

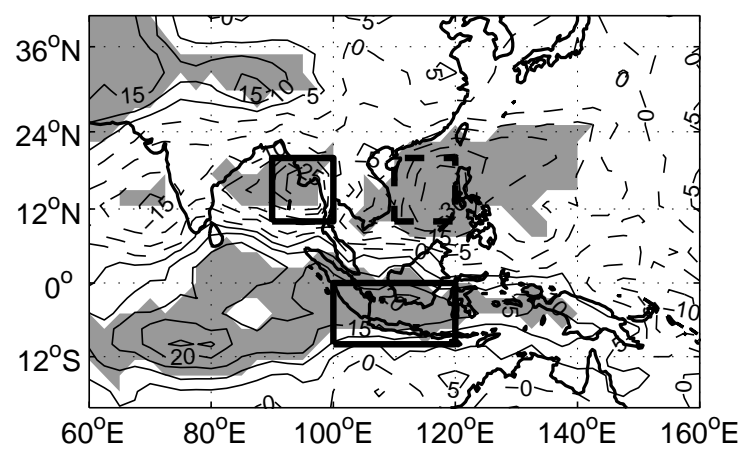


Figure 7

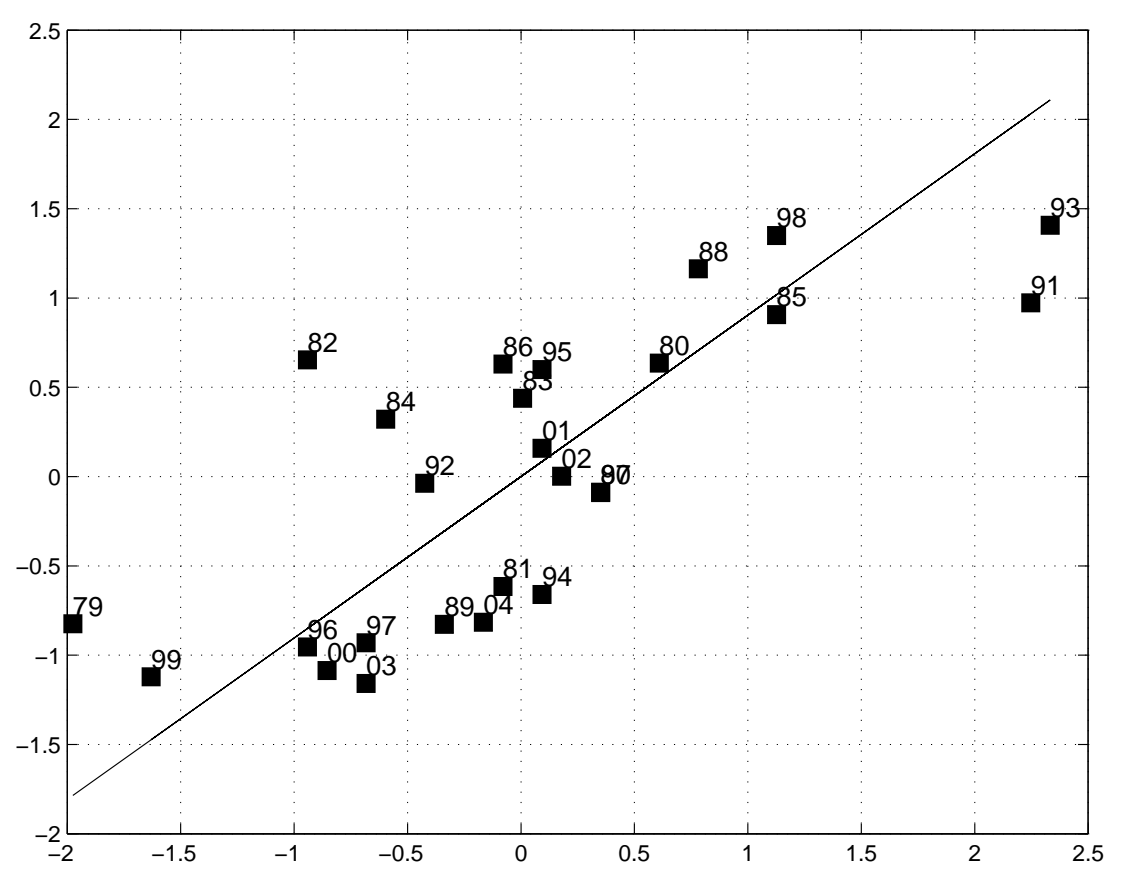

